PREPARED FOR THE U.S. DEPARTMENT OF ENERGY, UNDER CONTRACT DE-AC02-76CH03073

PPPL-3603

PPPL-3603

UC-70

Tritium Removal from Codeposits on Carbon Tiles

by a Scanning Laser

by

C.H. Skinner, C.A. Gentile, A. Carpe, G. Guttadora, S. Langish,

K.M. Young, W.M. Shu, and H. Nakamura

September 2001

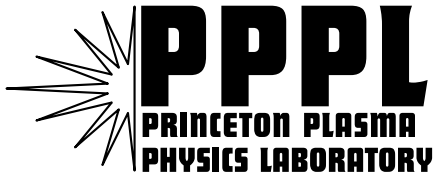

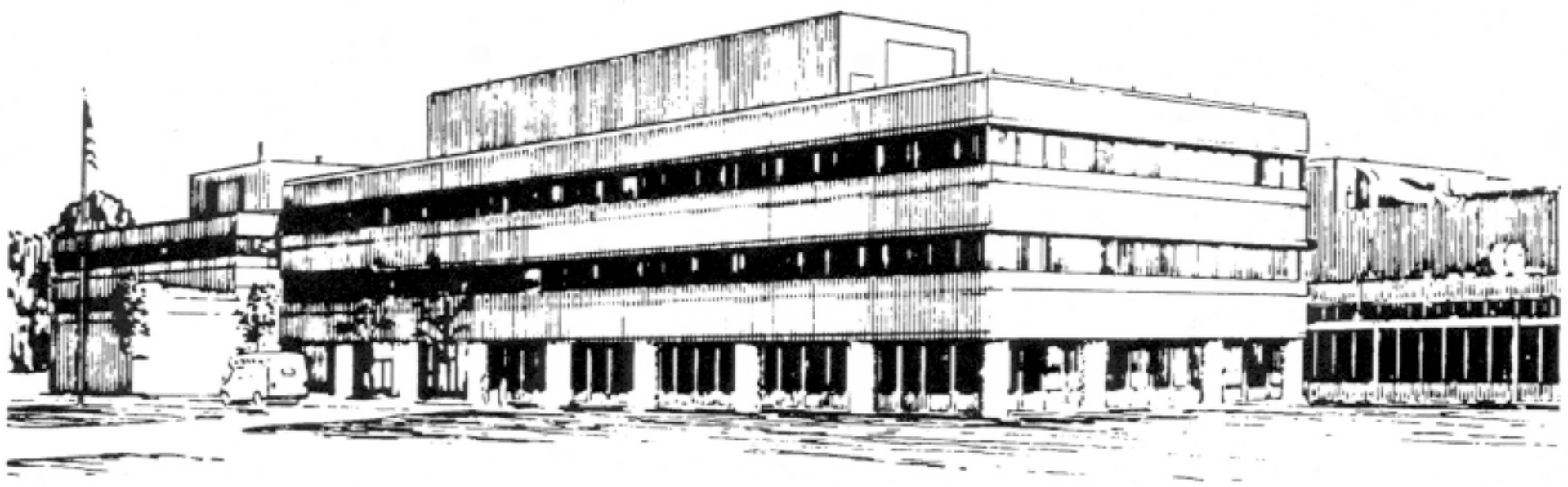

PRINCETON PLASMA PHYSICS LABORATORY PRINCETON UNIVERSITY, PRINCETON, NEW JERSEY 


\section{PPPL Reports Disclaimer}

This report was prepared as an account of work sponsored by an agency of the United States Government. Neither the United States Government nor any agency thereof, nor any of their employees, makes any warranty, express or implied, or assumes any legal liability or responsibility for the accuracy, completeness, or usefulness of any information, apparatus, product, or process disclosed, or represents that its use would not infringe privately owned rights. Reference herein to any specific commercial product, process, or service by trade name, trademark, manufacturer, or otherwise, does not necessarily constitute or imply its endorsement, recommendation, or favoring by the United States Government or any agency thereof. The views and opinions of authors expressed herein do not necessarily state or reflect those of the United States Government or any agency thereof.

\section{Availability}

This report is posted on the U.S. Department of Energy's Princeton Plasma Physics Laboratory Publications and Reports web site in Calendar Year 2001. The home page for PPPL Reports and Publications is: http://www.pppl.gov/pub_report/

DOE and DOE Contractors can obtain copies of this report from:

U.S. Department of Energy

Office of Scientific and Technical Information

DOE Technical Information Services (DTIS)

P.O. Box 62

Oak Ridge, TN 37831

Telephone: (865) 576-8401

Fax: (865) 576-5728

Email: reports@adonis.osti.gov

This report is available to the general public from:

National Technical Information Service

U.S. Department of Commerce

5285 Port Royal Road

Springfield, VA 22161

Telephone: 1-800-553-6847 or

(703) 605-6000

Fax: (703) 321-8547

Internet: http://www.ntis.gov/ordering.htm 


\title{
Tritium removal from codeposits on carbon tiles by a scanning laser.
}

\author{
C.H. Skinner, C.A. Gentile, A. Carpe, G. Guttadora, S. Langish, K.M. Young, \\ W.M. Shu ${ }^{\mathrm{a}}$, and H. Nakamura ${ }^{\mathrm{a}}$. \\ Princeton Plasma Physics Laboratory, Princeton, New Jersey, 08543 USA \\ ${ }^{a}$ Tritium Engineering Laboratory, JAERI, Ibaraki, Japan
}

\begin{abstract}
:
A novel method for tritium release has been demonstrated on codeposited layers on graphite and carbon-fiber-composite tiles from the Tokamak Fusion Test Reactor (TFTR). A scanning continuous wave Nd laser beam heated the codeposits to a temperature of $1200-2300 \mathrm{C}$ for 10 to 200 milliseconds in an argon atmosphere. The temperature rise of the codeposit was significantly higher than that of the manufactured tile material (e.g. $1770 \mathrm{C} \mathrm{cf.} 1080 \mathrm{C}$ ). A major fraction of tritium was thermally desorbed with minimal change to the surface appearance at a laser intensity of $8 \mathrm{~kW} / \mathrm{cm}^{2}$, peak temperatures above $1230 \mathrm{C}$ and heating duration $10-20 \mathrm{msec}$. In two experiments, $46 \%$ and $84 \%$ of the total tritium was released during the laser scan. The application of this method for tritium removal from a tokamak reactor appears promising and has significant advantages over oxidative techniques.
\end{abstract}

Keywords: tritium removal, tritium codeposition, lasers, nuclear fusion. 


\section{Introduction}

Tritium issues are central to the development of fusion power[1,2] and a significant milestone was reached when deuterium - tritium plasmas in TFTR and JET produced 10 and $16 \mathrm{MW}$ of fusion power respectively[3,4]. A large fraction of tritium fuel was retained inside the vacuum vessel of both TFTR and JET, principally by codeposition with carbon eroded from plasma facing components[5,6,7]. In TFTR, several weeks were needed for tritium removal after only 10-15 min of cumulative deuterium-tritium (DT) plasmas. The amount of tritium retained in future DT machines with carbon plasma facing components will scale-up with the long pulse high duty-cycle operation. The time before the administrative safety limit for maximum tritium inventory is reached is uncertain but is of the order of a hundred pulses[1]. The subsequent availability of the machine for plasma operations will depend on efficient and fast tritium removal. Besides tritium inventory control, tritium removal from the vessel wall is required to control plasma fuelling by tritium implanted in the wall and to reduce the tritium out-gassing during maintenance activities. Independent of safety limits, control of the in-vessel tritium inventory is also necessary to avoid exhausting the available tritium supply.

Significant progress in tritium removal technologies was made in support of the engineering design activities of the International Thermonuclear Experimental Reactor project (ITER) [2]. High temperature baking $(>1,000 \mathrm{~K})$ under vacuum is sufficient to remove nearly all the trapped tritium[8], but is currently not technically possible for a large tokamak. Thermo-oxidative erosion at temperatures above $570 \mathrm{~K}$, or oxygen plasma discharges have been found to be effective in laboratory experiments to remove tritium from tritium-containing films $[9,10,11,12]$. Major drawbacks of techniques using oxygen, especially at elevated temperature, include wall conditioning time to subsequently remove oxygen and recover normal plasma operation, 
potential damage to in-vessel components, and the cost of processing large quantities of the DTO exhaust[13]. Some oxygen-free techniques have been tried. Preliminary trials with $\mathrm{CO}_{2}$ pellet blast cleaning removed the surface layer of a DIII-D tile, but also severely eroded the tile[14]. Cathodic arc cleaning has been used to remove codeposited carbon films from stainless steel and tungsten surfaces[15]. No engineering-scale demonstration of tritium removal at the required rate has been performed to date on a tokamak.

Heating the tritiated codeposits by a scanning laser can release tritium without the deleterious effects of oxidation[16]. While bulk heating of a tokamak vacuum vessel to $1,000 \mathrm{~K}$ under vacuum is impractical, the tritium is located on a surface film and only this film needs to be heated. A scanning laser is a convenient way to locally heat the surface. Multi-kW, robotically controlled lasers are a mature technology for industrial manufacturing. For application to a tokamak the laser would be external to the vessel and the beam coupled via fiber optics to a remotely controlled scanning device inside the vessel. Early work showed the release of hydrogen isotopes by heating with nanosecond pulses from electron beams and lasers $[17,18,19,20]$. More recently picosecond laser pulses were used for in-situ measurements of hydrogen isotopes[21]. Excimer lasers have also been applied to tritium removal[22]. One issue with high power pulsed lasers is that ablation of the surface can compound the tritium removal problem by distributing tritiated debris in inaccessible regions in a tokamak.

The purpose of this work is a proof-of-principal demonstration of tritium release from a codeposited film on TFTR tiles by heating with a scanning continuous laser beam in a laboratory experiment. The parametric dependencies of the tritium release on laser focal intensity, scanning speed, surface temperature and ambient gas, the release products and any morphological changes in the surface were studied to provide data for practical implementation in a tokamak. 


\section{Modeling}

The temperature needed to release tritium depends on the transport of tritium in a codeposit at elevated temperatures, a process complicated by the porous, anisotropic structure of the codeposited layer. Tritium release in transient temperature excursions is sensitive to the slowest kinetics such as multistep low activation energy diffusion and is likely to be different to low temperature isochronal thermal desorption. The required laser intensity and exposure duration are governed by the thickness of the codeposited layer and the desired temperature excursion. Prior experiments[23] with a $30 \mathrm{~ns}$ pulsed ruby laser showed desorption of deuterium implanted in the top $100 \mathrm{~nm}$ of the surface at temperatures of order 1,700 $\mathrm{C}$ (depending on the type of graphite). Graphite and carbon-fiber-composite (CFC) materials are manufactured in a variety of forms and their thermal conductivity varies over a wide range depending on the microstructure and crystallite orientation. The thermal conductivity of amorphous carbon films has been measured at low (80-400 K) temperatures[24]. In the modeling, conductivity data for several forms of graphite and carbon fiber composite was used, and 1,700 $\mathrm{C}$ was taken as the target temperature.

Fig. 1 shows results from numerical modeling of surface heating[16]. For the case of pyrolitic graphite with heat flow perpendicular to the layer planes, the surface temperature was predicted to reach 2,000 $\mathrm{C}$ after a $3 \mathrm{~kW} / \mathrm{cm}^{2}$ heat pulse of duration $20 \mathrm{~ms}$. At a depth $50 \mu \mathrm{m}$ below the surface, the temperature is $926 \mathrm{C}$. A laser power of order a few $\mathrm{kW} / \mathrm{cm}^{2}$ appears to be suitable for heating $50 \mu \mathrm{m}$ codeposited layers.

\section{Experimental setup}

Multi-kW $\mathrm{CO}_{2}$, neodymium $(\mathrm{Nd})$ and diode lasers are available commercially. For the present proof-of-principle experiment we used a $\mathrm{Nd}$ laser system developed for laser marking 
purposes[25]. This is a multimode continuous wave laser with an output power up to $325 \mathrm{~W}$ at $1064 \mathrm{~nm}$ and with a specified beam divergence of $20 \mathrm{mrad}$. The output is steered by two galvanometer driven scanning mirrors that are pre-programmed via a PC computer and is focussed inside a vacuum chamber containing a tile specimen (Fig. 2). The maximum laser intensity measured inside the tile chamber was $248 \mathrm{~W}$. The original marking system had a working field of $150 \mathrm{~mm} \times 150 \mathrm{~mm}$ field, with a maximum focal spot velocity of $4 \mathrm{~m} / \mathrm{s}$. For the present work, the focal intensity was increased by adding a second lens (combined focal length $125 \mathrm{~mm}$ ). The scanning field was then $75 \mathrm{~mm}$ x $75 \mathrm{~mm}$ and maximum spot velocity $2 \mathrm{~m} / \mathrm{s}$. The focussed beam profile was too intense to measure with conventional beam profilers but a stationary laser spot 'drilled' a 1mm diameter hole in graphite. For most of the experiments the cube surface was positioned $12 \mathrm{~mm}$ from the focal plane. At this point the focal spot was approximately $2 \mathrm{~mm}$ diameter, and the estimated focal intensity inside the chamber approximately $8 \mathrm{~kW} / \mathrm{cm}^{2}$. A co-linear helium neon laser beam indicated the location of the $\mathrm{Nd}$ laser spot.

Tiles that had been exposed to tritium plasmas during the TFTR DT campaign were retrieved from the vacuum vessel[26] and cut up into cubes of edge dimension approximately $2 \mathrm{~cm}$. Both graphite (Union Carbide POCO AXF-5Q) and carbon fiber composite tiles (Fiber Materials Inc. 4D coarse weave) were used. The tile cubes were placed in a $20 \mathrm{~cm}$ diameter stainless steel chamber that had two $7.6 \mathrm{~cm}$ diameter windows arranged at 45 degrees for laser and pyrometer access. The laser access window was anti-reflection coated and the laser path was directed to a ceramic coated heat sink before and after each scan. The chamber was typically pumped and purged with argon 5 times, and then filled with 750 torr of argon.

A pyrometer[27] viewed the tile surface at 45 degrees to the $\mathrm{Nd}$ laser beam. It operated in the 1.58 to 1.8 micron spectral range and measured surface temperatures in the range $500 \mathrm{C}$ to 2300 
$\mathrm{C}$ with a specified accuracy of $1 \%$. It was calibrated by the manufacturer with a $99.4 \%$ emissivity black body furnace with the vacuum window and $\mathrm{Nd}$ laser rejection filter (below) in place. The response time (to $99 \%$ ) was $0.3 \mathrm{~ms}$. Macro optics were used to define a $0.7 \mathrm{~mm}$ by 1 mm measuring spot which was positioned with a through-the-lens sighting system. To avoid any possibility of scattered $1.064 \mathrm{~nm}$ light from the laser affecting the measurement, a rejection filter with transmission less than $1 \%$ at $1.064 \mathrm{~nm}, 0-30^{\circ}$ incidence and transmission greater than $80 \%$ at $1.4-1.8$ microns was used. The spectral emissivity of graphite at 1.7 microns wavelength and $1578 \mathrm{C}$ was measured to be $0.91[28]$, however the emissivity depends on surface roughness and the emissivity of codeposits is unknown. We report the apparent brightness temperature as indicated by the pyrometer for a blackbody. The true temperature of a gray body with emissivity 0.9 and brightness temperature of $1500 \mathrm{C}$ would be $1530 \mathrm{C}$, this is a small change compared to the experimental variations observed (sect. 4.1). The signal from the pyrometer was recorded by a 12 bit PCI analog input board in the PC computer at a digitization rate typically $10 \mathrm{kHz}$. A thermocouple was placed at the back of the cube to record bulk temperature changes.

Before and after each experiment the codeposited surface was imaged at normal incidence and 45 degrees with a digital microscope[29]. This microscope was also used to make video recordings of the incandescence from the laser spot on the cube.

Tritium release was measured in several ways. The principal instrument was an ion chamber[30,31] that recorded the tritium concentration in a closed loop circulation system. The dynamic range for this instrument is $1 \mathrm{mCi} / \mathrm{m}^{3}$ to $20,000 \mathrm{Ci} / \mathrm{m}^{3}$. The response is known to be different for different carrier gases because of differences in collision rates. The ion chamber was calibrated by releasing a small quantity of tritium at low laser power and flowing the gas through both the ion chamber and a Scintrex 209 tritium monitor in series in a closed loop. The Scintrex monitor is calibrated with standard gas containing $250 \mu \mathrm{Ci} / \mathrm{m}^{3}$ of tritium. A second calibration 
was performed by inserting an envelope containing a molecular sieve into the loop. This absorbs HTO, which is subsequently measured by liquid scintillation counting. The tritium absorbed by the molecular sieve was then compared to the decrease in the ion chamber reading. These two independent methods gave a calibration factor within $10 \%$, that was also consistent with earlier work on ion chamber calibration[32]. The calibration showed that for an argon atmosphere the true tritium concentration was the ion chamber reading times a factor of 0.54 . For air, the factor was $\mathrm{x} 0.69$.

A 'Differential Atmospheric Tritium Sampler' (DATS)[33] was used to measure the released HTO and HT fractions separately. The DATS absorbs HTO on a molecular sieve, and then oxidizes the HT with a palladium catalyst and absorbs this fraction on a separate molecular sieve. Before and after laser exposure, tritium activity on the surface of the cube was measured with an open wall ion chamber[34]. Any tritiated debris on the interior of the tile chamber was collected with cotton swabs and the tritium measured with a liquid scintillation counter.

\section{Tritium release experiments.}

A total of 12 cubes have been scanned by the $\mathrm{Nd}$ laser to date. These were cut from carbon fiber composite tiles $\mathrm{KC} 15, \mathrm{KC} 17$ and graphite tile KC22 from TFTR. Designator 'KC17 3D' indicates a cube cut from a TFTR tile from bay K, column C, row 17 [6] and the cube is from the $3^{\text {rd }}$ row up $4^{\text {th }}$ column to the right. An open wall ion chamber[34] was used to map the tritium distribution on tile $\mathrm{KC} 17$ before sectioning to cubes. The detector area was $6 \mathrm{~mm}$ diameter and the detector is sensitive to tritium in the top micron of the surface. The areal tritium density ranged between $60-190 \mu \mathrm{Ci} / \mathrm{cm}^{2}$ with an average of $106 \mu \mathrm{Ci} / \mathrm{cm}^{2}$.

A typical experiment proceeded as follows. After the cube was loaded in the chamber, it was connected to the pumping system and pump/purged 5 times with argon to change the atmosphere 
to argon. Cross hairs in the telescopic sight on the pyrometer were aligned to the co-linear helium neon laser spot on a surface typically positioned $12 \mathrm{~mm}$ in front of the $\mathrm{Nd}$ laser focal plane. Burn paper was used to detect and compensate for any misalignment between the helium neon and Nd lasers. The laser chamber was then brought into position and as evidenced by the helium laser spot on the cube surface reappearing in the pyrometer cross hairs, as in Fig. $2 \mathrm{~b}$. The helium neon laser was then scanned with a rectangular test pattern that was adjusted to define the border of the cube in terms of the programming parameters. Raster patterns on different areas of the cube surface were then programmed and tested by visual observation with the helium neon laser. These scanned either vertically or horizontally over specific areas of the cube surface with a line spacing typically $0.5 \mathrm{~mm}$ (Fig. 3). Since this spacing is less than the focal spot size a given position on the cube experienced first the fringe, then the center and then again the fringe of the laser spot in about 6 passes (Fig.4). To allow time to turn the Nd laser on and off, the program aimed the laser at the heat sink at the back of the laser chamber for 10 seconds before and after the raster scan. The PC digitizer was triggered just before the scan and the pyrometer data recorded. The scanning laser beam, viewed through laser safety glasses, produced a dazzlingly bright spot on the surface. The released tritium was circulated through the ion chamber which increased to a steady value over a few minutes.

\subsection{Variation of temperature rise with surface material.}

The conductivity of the codeposits is not known but is likely to be low because of its open porous structure[35]. This is advantageous for laser heating, as the temperature rise is higher and more localized to the codeposit. There are microscopic variations in temperature within the laser focal spot (see sect. 4.3) so that the reported temperature represents an average within the 0.7 $\mathrm{mm}$ viewing area of the pyrometer. Fig. 5 shows a comparison between the thermal response of a codeposit and the underlying graphite. In both experiments the laser intensity was $8 \mathrm{kw} / \mathrm{cm}^{2}$, 
scan speed $1000 \mathrm{~mm} / \mathrm{s}$, and atmosphere argon. The response of the codeposited side was measured first, and then the cube was rotated to bring the side cut by the saw to face the $\mathrm{Nd}$ laser. The peak temperature of the codeposited side was $1770 \mathrm{C}$, much higher than the $1080 \mathrm{C}$ measured for the graphite surface revealed by the sawcut.

Another cube, cut from a CFC tile showed an interesting feature (fig. 6) where part of the surface had a darker appearance, without much co-deposit. The temperature response was measured by aligning the pyrometer on the left and then the right of the front surface of the cube for laser scan conditions $8 \mathrm{kw} / \mathrm{cm}^{2}$, scan speed $50 \mathrm{~mm} / \mathrm{s}$, and atmosphere of argon. The peak temperature on the left was $1841 \mathrm{C}$ compared to $1181 \mathrm{C}$ on the right confirming that the temperature rise was very dependent on the surface morphology.

The emissivity may also change with the surface texture. To check the influence of the emissivity on the temperature measurement the adjacent cube (KC17-2A) was heated to $600 \mathrm{C}$ for several minutes by a defocussed continuous Nd laser spot. Spatially scanning the pyrometer from left to right over the different surface textures showed a change of only 19 degrees so changes in emissivity cannot account for the large change above. The CFC material, being a 4D weave, is expected to be approximately thermally isotropic. The highest temperature rise (slightly over $2300 \mathrm{C}$, the limit of the pyrometer) was seen for cube $\mathrm{KC} 17-2 \mathrm{G}$ which had a thick co-deposit. In contrast, cube $\mathrm{KC} 15-21 \mathrm{C}$ had a codeposit much smoother in appearance, and a scan at the same laser power and scan speed $\left(8 \mathrm{kw} / \mathrm{cm}^{2}, 1000 \mathrm{~mm} / \mathrm{s}\right)$ resulted in a peak temperature of only $1381 \mathrm{C}$ and released much less tritium (sect. 4.4).

In one case $(\mathrm{KC} 17-4 \mathrm{E})$ the $\mathrm{Nd}$ laser scanned the surface that originally faced the gap between tiles on the TFTR bumper limiter. A band approximately $1 \mathrm{~cm}$ wide, adjacent to the plasma facing surface showed the appearance of codeposition[36]. This experiment was performed 
before the full diagnostics were available, but visually there was a much more intense interaction of the $\mathrm{Nd}$ laser in the codeposition region. It is clear that the temperature rise depends strongly on the morphology of the surface layer with codeposited surfaces reaching much higher temperatures than the manufactured material. In general, co-deposits on graphite and CFC tiles behaved similarly.

\subsection{Temperature rise vs. scan speed}

The depth of heat penetration depends on the duration of the exposure which is controlled by varying the scan speed. For a fixed laser power of $8 \mathrm{~kW} / \mathrm{cm}^{2}$ and argon atmosphere, the scan speed was varied from $50-2000 \mathrm{~mm} / \mathrm{s}$ in a sequence of raster scans on two cubes (Fig. 7). The raster was moved to a fresh area for each scan. For an idealised homogeneous material, the temperature rise would scale with the square root of the heat pulse duration. The peak temperature deviates markedly from this relation below scan speeds of $1000 \mathrm{~mm} / \mathrm{s}$ as additional heat absorption mechanisms become active.

To compare the evolution of the surface temperature at different scan speeds, the time evolution recorded by the pyrometer was converted to a spatial variation by multiplying the elapsed time by the scan speed. Fig. 8 shows a comparison of temperature evolution at scan speeds of 50 and $400 \mathrm{~mm} / \mathrm{s}$. The steep temperature drop at the lower speed is likely caused by ejection of material exposing the cooler substrate. It appears that at slow speeds laser energy is going to material ablation. The spatial transition between the more insulating codeposit and the more conducting substrate will also affect the dependence of temperature on heat pulse duration. Another potential energy sink is the endothermic steam reaction[37]. The temperature of the back side of the cube was measured by a thermocouple and typically rose by 5-10 degrees $\mathrm{C}$. 
4.3 Microscope images of the surface before, during and after the laser scan.

Microscope images were taken of each cube before and after the laser scan. The cubes were viewed normal to the surface and at 45 degrees. Fig. 9 shows a cube before and after a fast laser scan $1000 \mathrm{~mm} / \mathrm{s}$ at full laser power, $8 \mathrm{~kW} / \mathrm{cm}^{2}$ in an argon atmosphere. There is slight color change as a result of the laser scan but the codeposit appears undisturbed even though the surface temperature reached $1770 \mathrm{C}$ and $18 \mathrm{mCi}$ of tritium was released (sect. 4.5). The duration of the heat pulse at this scan speed is $10 \mathrm{~ms}$ (fig. 5). These conditions are a good match to the modeling predictions for the heat flux needed to heat a $50 \mu \mathrm{m}$ thick layer to above $1000 \mathrm{C}$ (sect. 2).

The digital microscope could be configured to record videos at 30 frames/sec and Fig. 10 shows four still images from a video taken through a x100,000 neutral density filter of the intense incandescence from the interaction of the Nd laser with the surface of cube KC17-2B. In this case the scan speed was $50 \mathrm{~mm} / \mathrm{sec}$. There is some elongation of the image in the horizontal direction due to the finite shutter open time. It is clear that the interaction is not uniform and 100 $-400 \mu \mathrm{m}$ hot spots are apparent. Microscopic variations of the thermal conduction from surface grains to the underlying material lead to large spatial variations in temperature and the temperature recorded by the pyrometer then is an average over these hot spots within the $0.7 \mathrm{~mm}$ viewing area of the pyrometer. The incandescence is much brighter in Fig. 10 (a) and (b) taken from the light gray area (seen on the left side of Fig. 6), consistent with the pyrometer measurements (sect. 4.1).

The thermal response of plasma facing materials is typically calculated with coefficients for bulk materials; for example to check if the maximum temperature is below the threshold for radiation induced sublimation. These images illustrate very clearly that the thermal response depends on 
the microstructure of the co-deposit and reliable predictions for deposition areas need to be based on experiments with tokamak generated codeposits.

\subsection{Tritium release in air or argon atmospheres.}

The atmosphere in the vacuum chamber was circulated through an ion chamber that measured the tritium concentration. The total tritium release was then calculated by multiplying the concentration by the total volume of the system. The role of the ambient gas on the products of the laser interaction was measured in sequential experiments in air and argon. The left hand side of the codeposited surface on a cube was scanned by the $\mathrm{Nd}$ laser $\left(8 \mathrm{~kW} / \mathrm{cm}^{2}, 50 \mathrm{~mm} / \mathrm{s}\right)$ in an atmosphere of room air and the tritium release recorded. After the ion chamber reading was steady, a 'Differential Atmospheric Tritium Sampler' (DATS)[33] was inserted into the circulation loop and was used to measure the HTO and HT. The atmosphere in the chamber was then purged with argon 5 times and the right hand side of the cube surface scanned by the $\mathrm{Nd}$ laser with identical laser parameters. Sampling with a residual gas analyzer showed $99 \%$ of the gas to be argon. The tritium release was measured as before, except that only the HTO could be measured by the DATS, as no external oxygen was available to oxidize the HT. The results are shown in Table 1. With an air atmosphere, the major fraction of tritium is released in the oxide form. With an argon atmosphere this fraction is much less, but not zero. While oxygen and water vapor are excluded from the chamber, oxygen has been detected in the tile surface by x-ray photoelectron spectroscopy at an atomic concentration (excluding $\mathrm{H}$-isotopes) of $20 \%-50 \%$ [38]. This presumably originates from water absorption from air humidity by the tile in the 4year period after the termination of plasma operations on TFTR. In an operating tokamak, wall conditioning techniques are used to remove oxygen from the plasma facing surfaces and the HTO fraction in the release is expected to be very small. It can be seen that the total tritium $(\mathrm{HTO}+\mathrm{HT})$ measured by the DATS is less that measured by the ion chamber. The discrepancy 
could be caused by wall absorption or the presence of tritiated hydrocarbons that were not oxidized by the catalyst.

Any debris from the laser interaction that coated the inside walls of the test chamber was collected by a Q-tip swab and the tritium content measured in a liquid scintillation counter. Extrapolating the sampled area to the whole inside surface of the vacuum chamber typically gave an total of $1-3 \mu \mathrm{Ci}$. This is very small compared to the tens of mCi released.

\subsection{Tritium release vs. peak temperature}

Fig. 11 shows a plot of the released tritium as a function of the peak temperature on the tile surface. The laser power was $8 \mathrm{~kW} / \mathrm{cm}^{2}$ and atmosphere argon. A fresh surface was used for each scan which covered 1/4 of the cube area. Much of the scatter in the data is due to the nonuniformity of tritium across the tile. An early experiment, done before the in-line ion chamber was in place, used a lower intensity focal spot of approximately $1-2 \mathrm{~kW} / \mathrm{cm}^{2}$ on KC17 cube $4 \mathrm{E}$. The peak temperature was $1230 \mathrm{C}$, maximum duration above $500 \mathrm{C}$ was $95 \mathrm{~ms}$ and the surface tritium activity decreased only from 76 to $51 \mu \mathrm{Ci} / \mathrm{cm}^{2}$. The temperature threshold is not precisely defined by the data, but it appears temperatures above $1230 \mathrm{C}$ are needed to release large fractions of tritium.

\subsection{Tritium release vs. heat pulse duration.}

The heat penetration depth was controlled by varying the local heating time through the scan speed. Since the pyrometer viewed a $0.7 \mathrm{~mm}$ area, the spacing between lines in the raster was set to $0.5 \mathrm{~mm}$ to ensure the peak temperature was recorded. The overall laser spot diameter was approximately $2 \mathrm{~mm}$ and this meant that an individual spot would first experience the fringe of the laser spot, then successive passes would bring the spot across the pyrometer view area generating several temperature excursions of increasing, then decreasing peak temperature (fig. 
4). Repeating a raster on the same area of $\mathrm{KC} 17$ cube $4 \mathrm{C}$ released $1.7 \mathrm{mCi}$ on the first scan and then $0.14 \mathrm{mCi}$. For $\mathrm{KC} 22$ cube $6 \mathrm{E}$ the raster spacing was doubled to $1 \mathrm{~mm}$ and this was then repeated with the pattern shifted by $0.5 \mathrm{~mm}$. The tritium released was $12.1 \mathrm{mCi}$ in the first raster and $2.2 \mathrm{mCi}$ in the second. With this spacing the pyrometer recorded two excursions above 1000 C. It appears that most of the tritium is released in one or two heat pulses. Fig. 12 plots the maximum duration the pyrometer temperature was above $500 \mathrm{C}$ in a single pass. It can be seen that the tritium release is not a strong function of the duration. A heating pulse of order $10 \mathrm{~ms}$ and temperature excursion to $1500 \mathrm{C}$ seems optimal for removing tritium with minimal change to the surface morphology. The $10 \mathrm{~ms}$ duration is consistent with heat penetration a $50 \mu \mathrm{m}$ thick codeposit (sect.2). Measurements of the thickness of the codeposited layer on this tile are not yet available, however previous measurements of deuterium codeposits from TFTR were of a $50 \mu \mathrm{m}$ scale[35].

\subsection{Residual tritium}

Baking in air at temperatures above $350 \mathrm{C}$ is known to remove almost all the tritium from a codeposited layer[8] and this technique was used on two cubes to measure tritium remaining after a laser scan. The plasma facing surface of $\mathrm{KC} 22$ cube $6 \mathrm{E}$ was scanned by the laser at 8 $\mathrm{kw} / \mathrm{cm}^{2}$, scan speed $1000 \mathrm{~m} / \mathrm{s}$. The maximum temperature was $1770 \mathrm{C}$ and $18 \mathrm{mCi}$ of tritium was released. Measurements of surface tritium with an open wall ion chamber showed the areal concentration decreasing from 99 to $29 \mu \mathrm{Ci} / \mathrm{cm}^{2}$. The cube was rotated 90 degrees and heated with a stationary defocussed $100 \mathrm{~W} \mathrm{Nd}$ laser beam to $450 \mathrm{C}$ for 40 minutes in air to release the remaining tritium by oxidation. The temperature was measured by a thermocouple on the back side of the cube. This laser 'bake' released $21 \mathrm{mCi}$ of tritium and the surface tritium decreased from $29 \mu \mathrm{Ci} / \mathrm{cm}^{2}$ to zero. The fraction of the total tritium that was released by the laser scan was then $46 \%$. 
In the experiments described above the cube surface was positioned $12 \mathrm{~mm}$ from the focal plane of the laser. The next cube (KC22 cube 6C) was positioned at the focal plane and focussed laser intensity estimated at $31 \mathrm{~kW} / \mathrm{cm}^{2}$. The surface temperature peaked at $2031 \mathrm{C}$ and the raster created visible tracks on the surface indicating some loss of surface material. The scan was repeated three times releasing $22.6,3.3$ and $1.9 \mathrm{mCi}$, i.e. a total of $28 \mathrm{mCi}$. The subsequent bake released only $5.3 \mathrm{mCi}$, so that the fraction of the total tritium released by the laser scan was encouragingly high at $84 \%$.

The Nd laser is multimode and the intensity profile at the focus likely to be irregular. In the future we plan to use a fiber optic to transmit the laser beam to the scan head and this should help smooth and control the focal intensity and release a high fraction of the tritium with minimal change to the morphology of the codeposited surface.

\section{Applications.}

The measurements reported above indicate a strong potential for laser scanning to remove tritium from codeposited layers in a DT next-step device. In a scaled-up system we envisage a multikilowatt laser beam delivered via fiber optics to a scanning head on a robotic arm or a mobile robot inside the vessel. A line focus would be convenient for covering large areas of tile. Energetically, $30 \mathrm{MJ}$ are needed to heat the top $100 \mu \mathrm{m}$ of a $50 \mathrm{~m}^{2}$ codeposited area from 400 to $2000 \mathrm{C}$ and this corresponds to the output of a $3 \mathrm{~kW}$ laser for 3 hours. Areas in the gaps in between tiles would need specialized optics to deliver the beam. The temperature excursion would also release volatile impurities from the tiles and improved wall conditioning may prove a significant collateral benefit to subsequent plasma operations. Clearly much work remains to be

done to develop this technique at an engineering scale, however the initial results show clearly that tritium can be released without the deleterious effects of oxidation. 
Plasma facing components in a tokamak experience high heat fluxes in off normal events such as ELMs and disruptions. E-beams, plasma devices and lasers are used to simulate these effects in the laboratory[2]. The different thermal response of a codeposit compared to the manufactured graphite, clearly evident in this work, underlines the fact that the morphology and composition of plasma facing surfaces are determined by the discharges in the tokamak and have properties different to the manufactured components. It is important to test the effects of disruptions on realistic codeposits. A laser intensity of $8 \mathrm{~kW} / \mathrm{cm} 2$ for $200 \mathrm{~ms}$ duration resulted in major surface damage (in contrast to short exposure times that cause minimal change to the surface (fig. 9)). In comparison a disruption in ITER is expected to generate a heat flux of $1,000 \mathrm{~kW} / \mathrm{cm}^{2}$ for $1-10$ ms although much of this will be attenuated by vapor shielding. Previous disruption simulation experiments[39, 40] used pulsed lasers of $0.1-0.3 \mathrm{~ms}$ duration. A scanning focussed laser beam offers a new way to study the interaction of very high heat fluxes with tokamak generated codeposits at relevant durations.

In summary, a major fraction of the tritium trapped in a codeposited layer during the DT campaign on TFTR was released by heating with a scanning laser beam. This technique offers the potential for tritium removal in a next step DT device without the use of oxidation and the associated deconditioning of the plasma facing surfaces and expense of processing large quantities of tritium oxide.

\section{Acknowledgments}

We wish to acknowledge informative discussions with D. Cahill, R. Causey, J. Davis, G. Federici, A.A. Haasz, A. von Keudell, R-D. Penzhorn, R. Reichle, and the dedicated work of the tritium group and collaborators at PPPL. We thank J. Dong, A. Planetta and the PPPL health physics group for supporting these measurements. Financial support was provided by the Annex 
IV to the JAERI/DOE Implementing Arrangement on Cooperation in Fusion Research and Development, and U.S. DOE Contract Nos. DE-AC02-76CH0307. 
Table 1

Comparison of tritium release in argon and air (KC17 cube 1E).

\begin{tabular}{cccc}
\hline Atmosphere & $\begin{array}{c}\text { Ion Chamber } \\
(\mathrm{mCi})\end{array}$ & $\begin{array}{c}\text { DAT HTO } \\
(\mathrm{mCi})\end{array}$ & $\begin{array}{c}\text { DAT HT } \\
(\mathrm{mCi})\end{array}$ \\
\hline air & 8.3 & 4.8 & 0.7 \\
argon & 6.9 & 1.0 & not measured. \\
\hline
\end{tabular}




\section{Figure Captions:}

Fig. 1 Numerical calculation of temperature vs. time for pyrolytic perp. graphite under a 3 $\mathrm{kW} / \mathrm{cm}^{2}$ heat flux for $20 \mathrm{~ms}$. The curves represent the temperature at the depths indicated below the surface.

Fig. 2 Schematic of experimental setup, (a) shows the plan view and (b) the vertical cross section with the pyrometer.

Fig. 3 Schematic of $\mathrm{Nd}$ laser raster pattern used on $\mathrm{KC17}$ cube 2B (fig. 6). Zone one and two are line patterns were used for video recording of the laser interaction (fig. 10). The lower 4 patterns measured the response of the different textured surfaces to the laser at powers of 91 and $242 \mathrm{~W}$.

Fig. 4 Temperature history of the location viewed by the pyrometer during a raster scan for laser power of $8 \mathrm{~kW} / \mathrm{cm}^{2}$, scan speed $1000 \mathrm{~m} / \mathrm{s}$ on $\mathrm{KC} 17$ cube $1 \mathrm{C}$.

Fig. 5 Comparison of the large difference between the thermal response of a codeposited layer and the graphite substrate to the $\mathrm{Nd}$ laser. The experimental conditions were the same in both cases, except that either the codeposited side or cut side faced the $\mathrm{Nd}$ laser. Note the pyrometer does not read below $500 \mathrm{C}$.

Fig. 6 Light microscope image of different surface textures on codeposit on KC17 cube $2 \mathrm{~B}$. The image covers $11 \mathrm{~mm}$ in the horizontal direction.

Fig. 7 Peak temperature vs. scan speed for two cubes: circles are KC17 cube 1C and crosses KC17 cube $4 \mathrm{C}$. The dashed line represents an idealized inverse square root dependence of peak temperature on scan speed.

Fig. 8 Temperature recorded by pyrometer on $\mathrm{KC} 17$ cube $4 \mathrm{C}$ at scan speeds of $50 \mathrm{~mm} / \mathrm{s}$ and $400 \mathrm{~mm} / \mathrm{s}$. The horizontal axis represents the distance between the pyrometer viewing spot and the scanning laser spot. The peak temperature is similar, but there is a sharp 
temperature decrease at $50 \mathrm{~mm} / \mathrm{s}$, possibly caused by ejection of material exposing the cooler substrate.

Fig. 9 Microscope images taken normal to the surface of $\mathrm{KC} 17$ cube $6 \mathrm{E}$ surface before (top) and after (bottom) a Nd laser scan $\left(8 \mathrm{~kW} / \mathrm{cm}^{2}, 1000 \mathrm{~mm} / \mathrm{s}\right)$. At this high scan speed there is very little difference in the appearance even though the surface was heated to $1770 \mathrm{C}$ (fig. 5) by the laser and $18 \mathrm{mCi}$ of tritium released. The image covers $7 \mathrm{~mm}$ in the horizontal direction.

Fig. 10 Still images from a video taken of the Nd laser interacting with the surface of KC17 cube 2B. The laser power was $8 \mathrm{~kW} / \mathrm{cm}^{2}$, atmosphere argon, and the scan was in the horizontal direction at a speed of $50 \mathrm{~mm} / \mathrm{s}$. Each frame covers $4.5 \mathrm{~mm}$ in the horizontal direction. Frames (a) and (b) are from the left, light gray area as seen in fig. 6, frames (c) and (d) from the blacker area on the right. The light emission was attenuated by x100,000 with a neutral density filter. Micro 'hot spots' are evident.

Fig. 11 Tritium released vs. peak temperature on tile surface. The plot shows data from cubes: KC17-3C, KC17-4C, KC17-1C, KC17-2G and KC15-21C.

Fig. 12 Tritium release vs. maximum duration of temperature excursion above $500 \mathrm{C}$. The plot shows data from cubes: KC17-3C, KC17-4C, KC17-1C, KC17-2G and KC15-21C. 


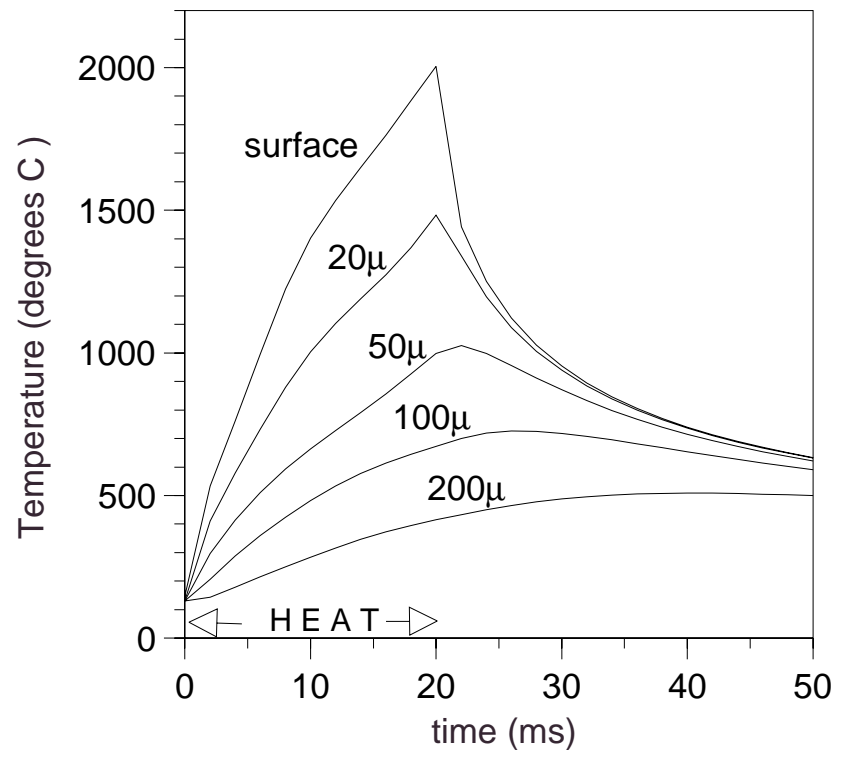

Fig. 1 Numerical calculation of temperature vs. time for pyrolytic perp. graphite under a 3 $\mathrm{kW} / \mathrm{cm}^{2}$ heat flux for $20 \mathrm{~ms}$. The curves represent the temperature at the depths indicated below the surface. 


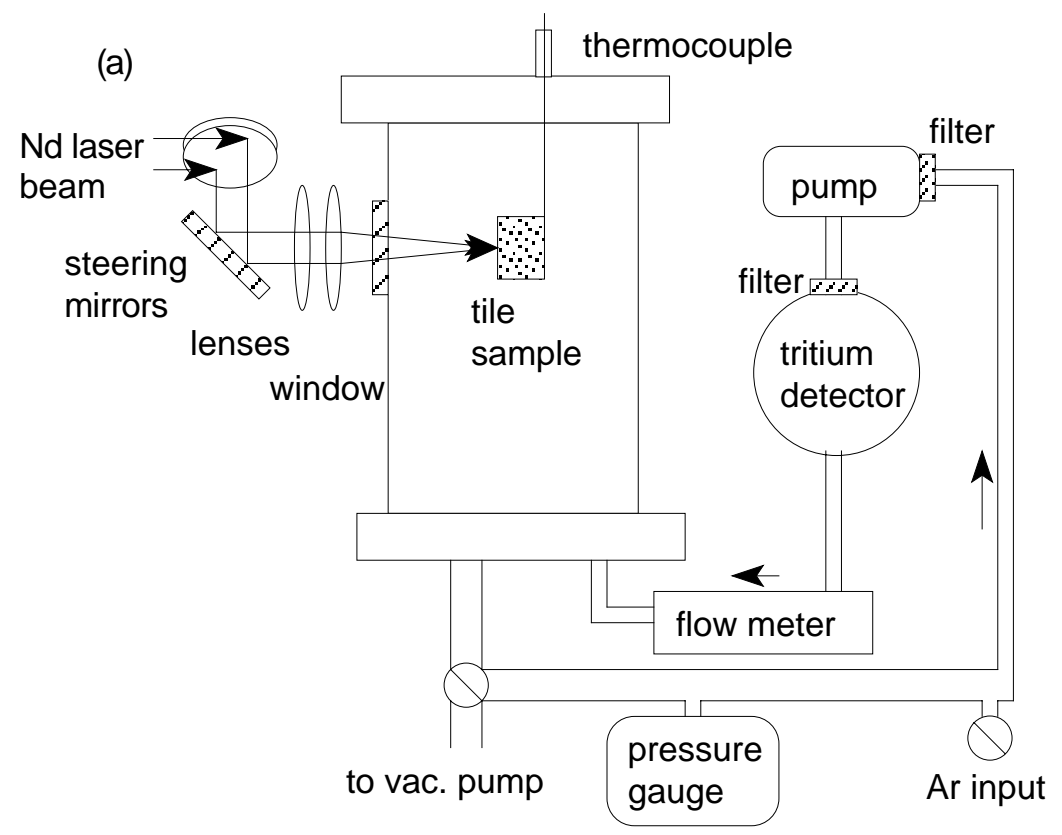

(b)

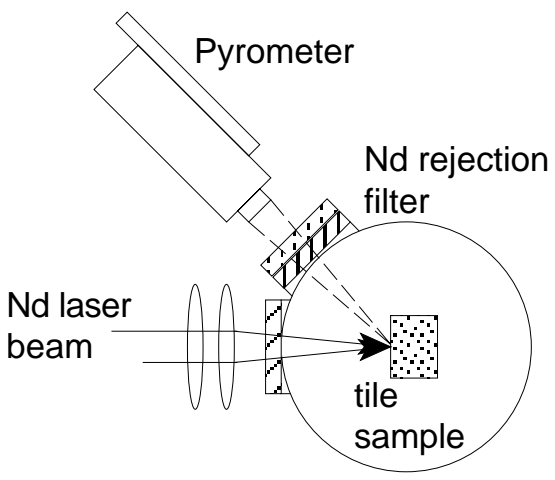

Fig. 2 Schematic of experimental setup, (a) shows the plan view and (b) the vertical cross section with the pyrometer. 


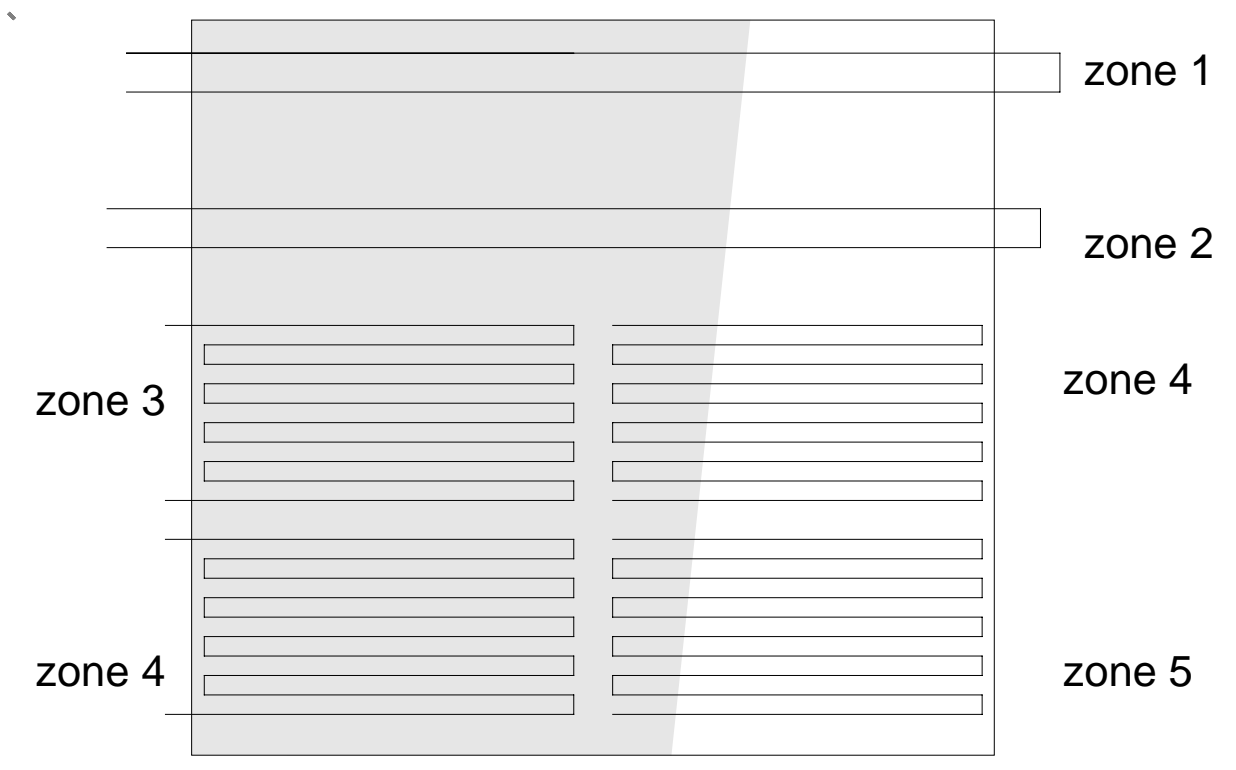

Fig. 3 Schematic of $\mathrm{Nd}$ laser raster pattern used on $\mathrm{KC} 17$ cube $2 \mathrm{~B}$ (fig. 6). Zone one and two are line patterns were used for video recording of the laser interaction (fig. 10). The lower 4 patterns measured the response of the different textured surfaces to the laser at powers of 91 and $242 \mathrm{~W}$. 


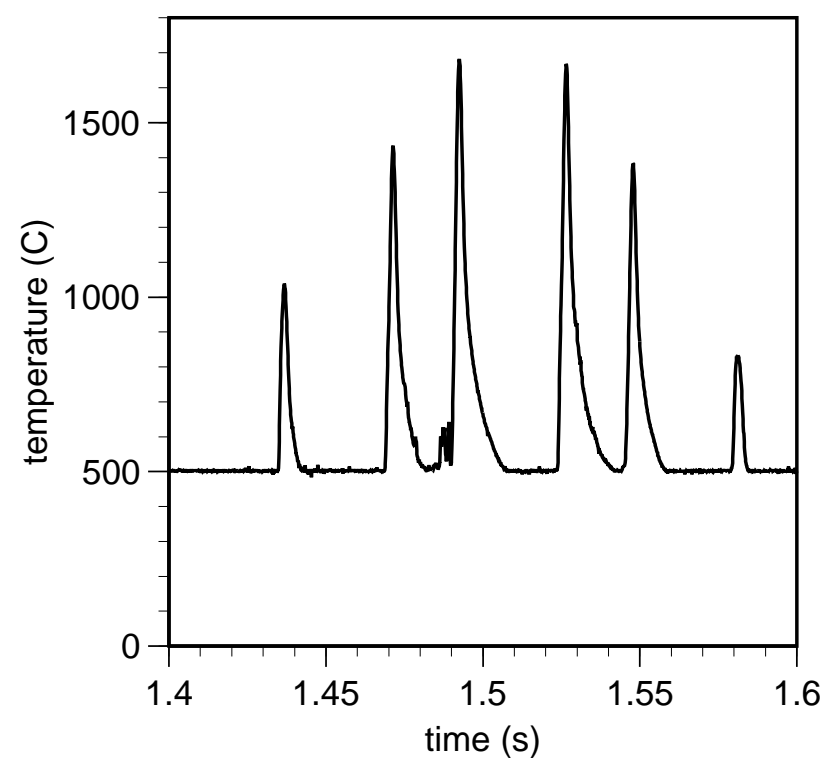

Fig. 4 Temperature history of the location viewed by the pyrometer during a raster scan for laser power of $8 \mathrm{~kW} / \mathrm{cm}^{2}$, scan speed $1000 \mathrm{~m} / \mathrm{s}$ on KC17 cube $1 \mathrm{C}$. 


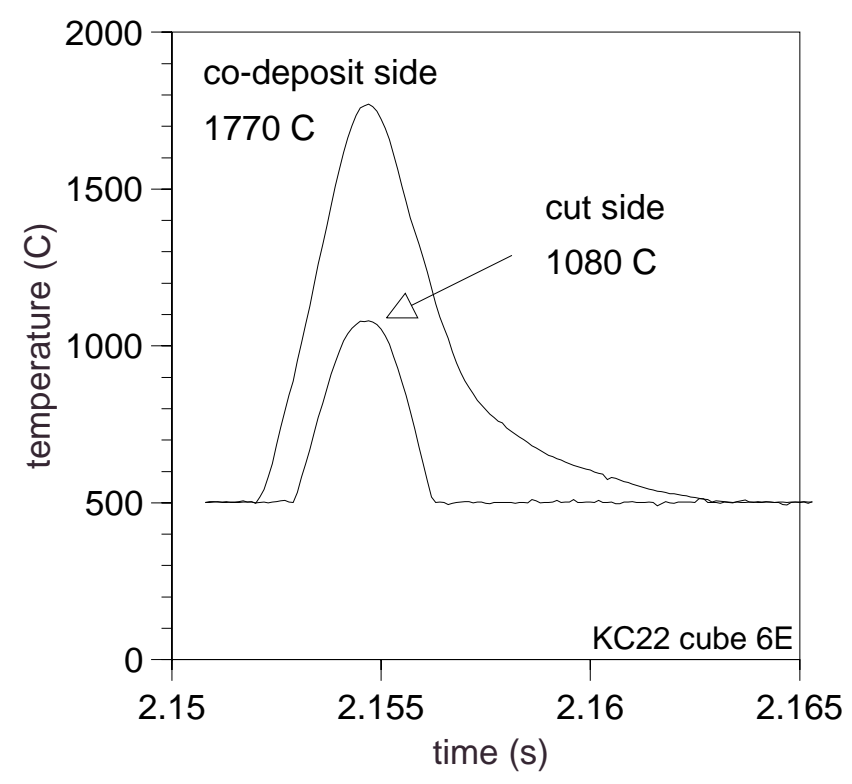

Fig. 5 Comparison of the large difference between the thermal response of a codeposited layer and the graphite substrate to the Nd laser. The experimental conditions were the same in both cases, except that either the codeposited side or cut side of the cube faced the $\mathrm{Nd}$ laser. Note the pyrometer does not read below $500 \mathrm{C}$. 


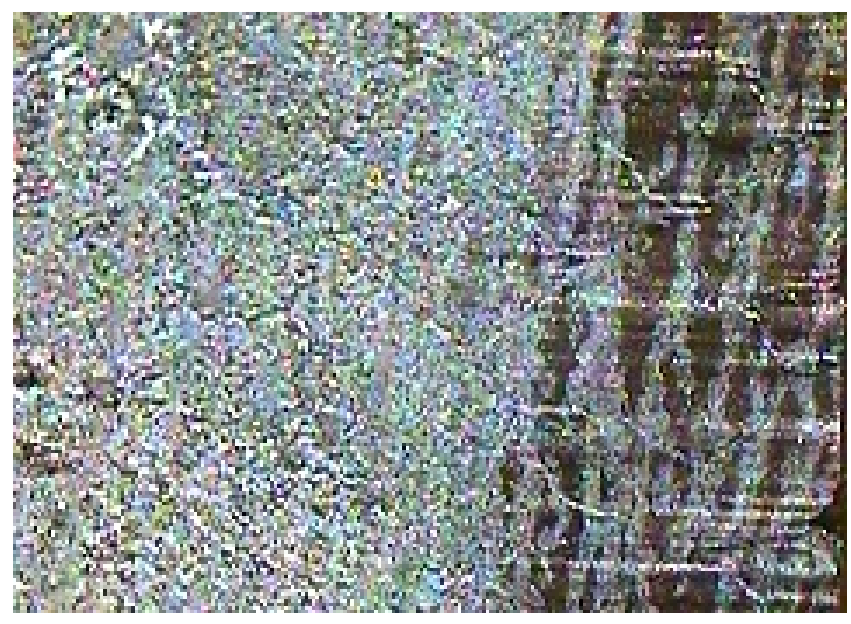

Fig. 6 Light microscope image of different surface textures on codeposit on KC17 cube 2B. The image covers $11 \mathrm{~mm}$ in the horizontal direction. 


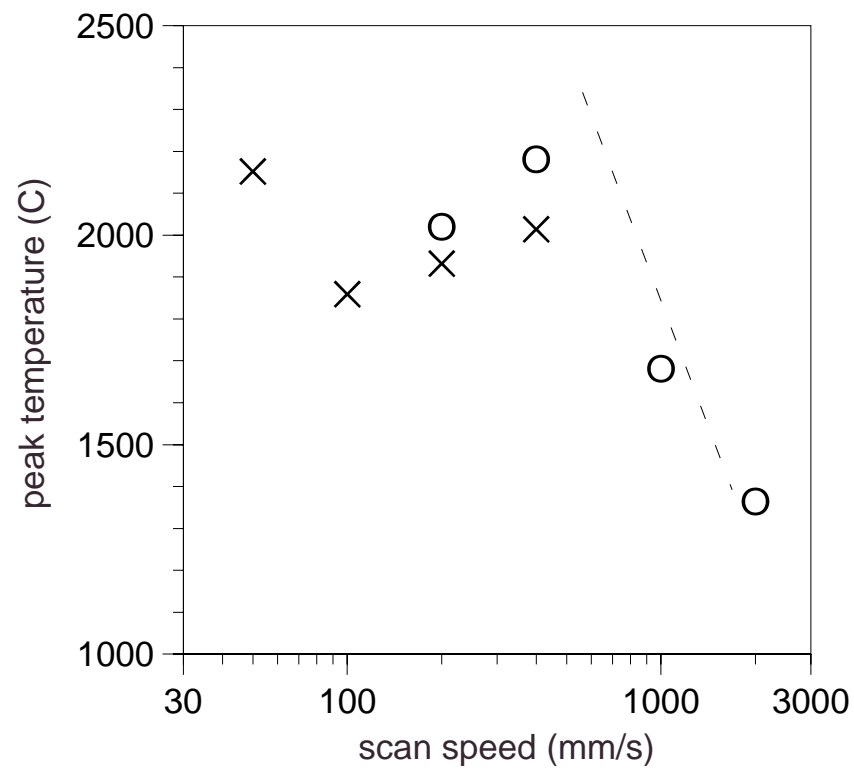

Fig. 7 Peak temperature vs. scan speed for two cubes: circles are for $\mathrm{KC} 17$ cube $1 \mathrm{C}$ and crosses KC17 cube 4C. The dashed line represents an idealized inverse square root dependence of peak temperature on scan speed. 


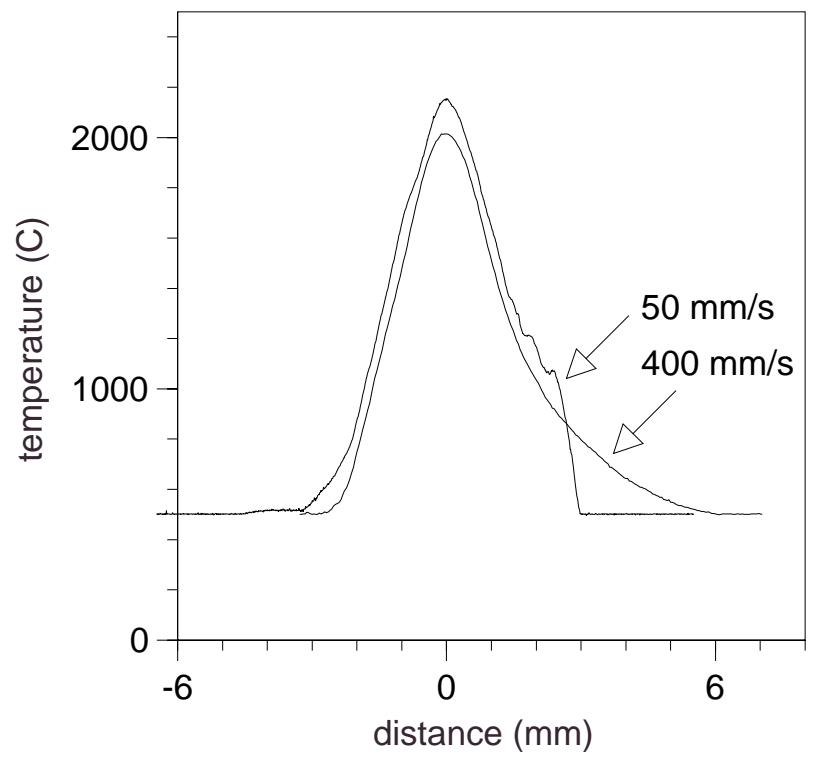

Fig. 8 Temperature recorded by pyrometer on KC17 cube $4 \mathrm{C}$ at scan speeds of $50 \mathrm{~mm} / \mathrm{s}$ and 400 $\mathrm{mm} / \mathrm{s}$. The horizontal axis represents the distance between the pyrometer viewing spot and the scanning laser spot. The peak temperature is similar, but there is a sharp temperature decrease at $50 \mathrm{~mm} / \mathrm{s}$, possibly caused by ejection of material exposing the cooler substrate. 

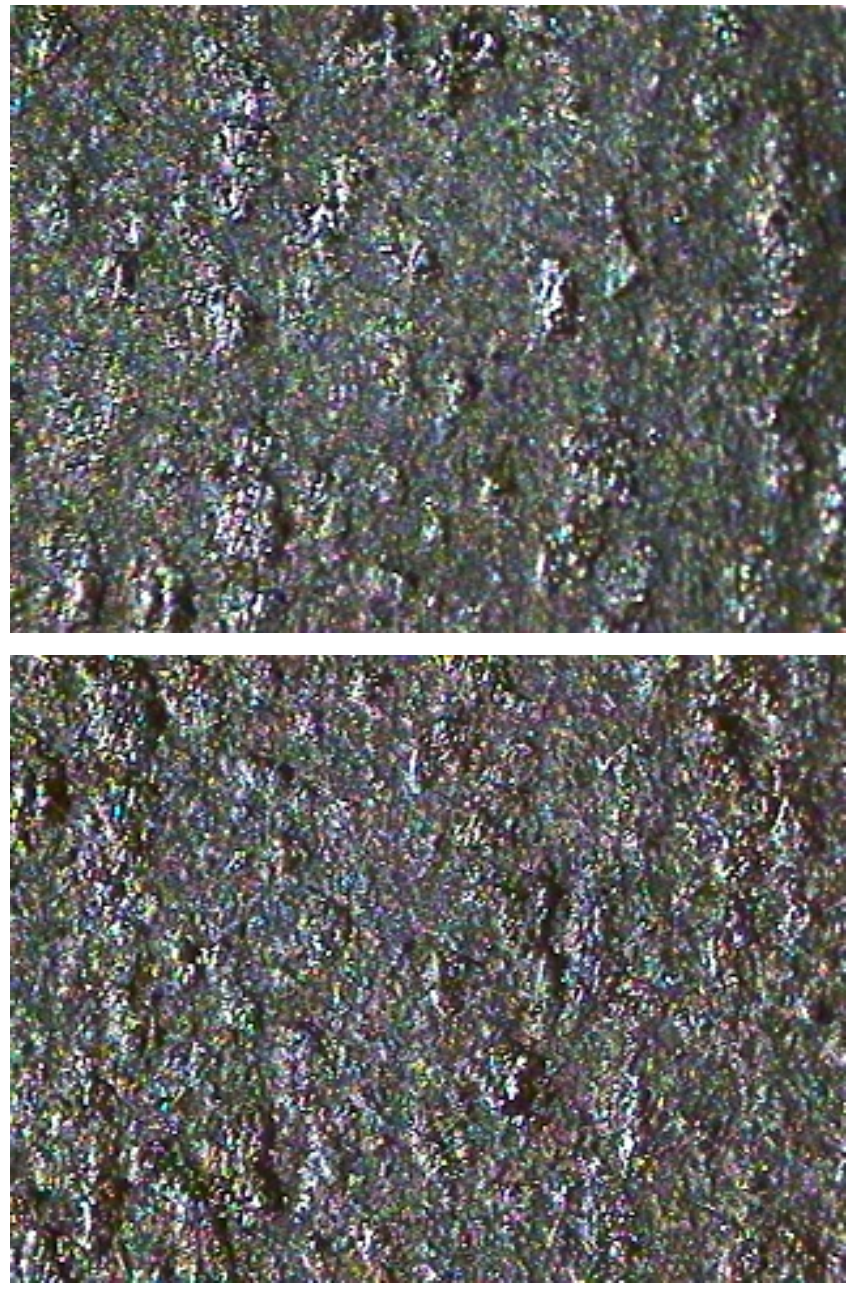

Fig. 9 Microscope images taken normal to the surface of $\mathrm{KC} 17$ cube $6 \mathrm{E}$ surface before (top) and after (bottom) a Nd laser scan $\left(8 \mathrm{~kW} / \mathrm{cm}^{2}, 1000 \mathrm{~mm} / \mathrm{s}\right)$. At this high scan speed there is very little difference in the appearance even though the surface was heated to $1770 \mathrm{C}$ (fig. 5) by the laser and $18 \mathrm{mCi}$ of tritium released. The image covers $7 \mathrm{~mm}$ in the horizontal direction. 

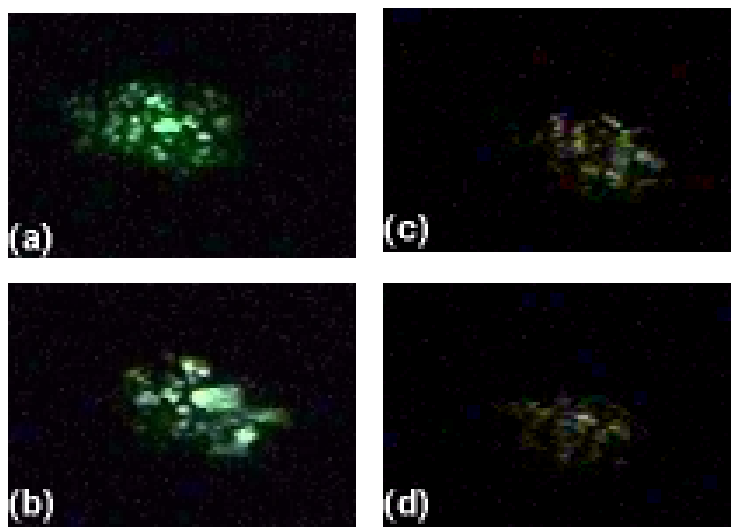

Fig. 10 Still images from a video taken of the Nd laser interacting with the surface of $\mathrm{KC} 17$ cube 2B. The laser power was $8 \mathrm{~kW} / \mathrm{cm}^{2}$, atmosphere argon, and the scan was in the horizontal direction at a speed of $50 \mathrm{~mm} / \mathrm{s}$. Each frame covers $4.5 \mathrm{~mm}$ in the horizontal direction. Frames (a) and (b) are from the left, light gray area as seen in fig. 6; frames (c) and (d) from the blacker area on the right. The light emission was attenuated by $x 100,000$ with a neutral density filter. Micro 'hot spots' are evident. 


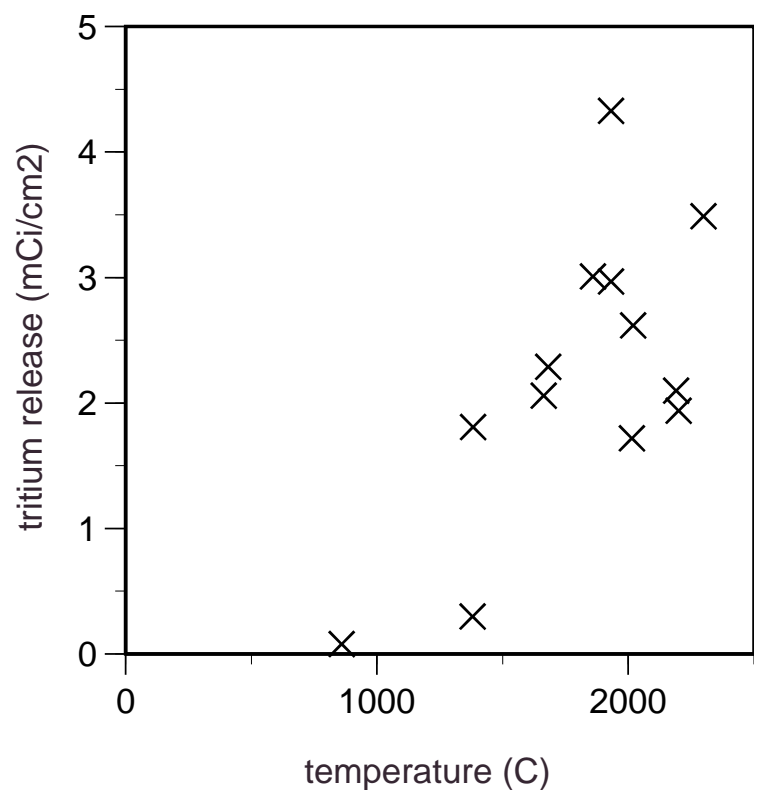

Fig. 11 Tritium released vs. peak temperature on tile surface. The plot shows data from cubes: KC17-3C, KC17-4C, KC17-1C, KC17-2G and KC15-21C. 


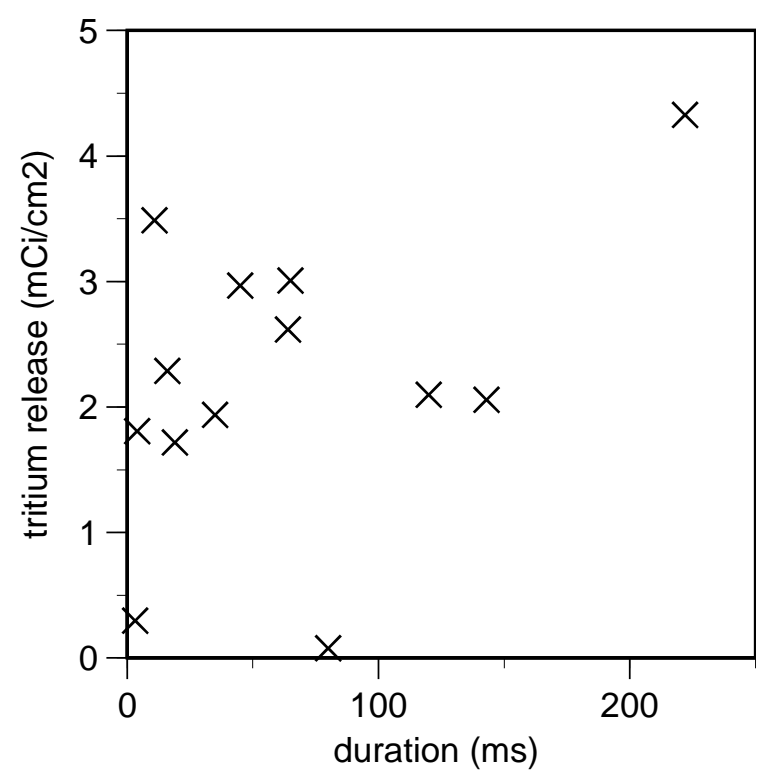

Fig. 12 Tritium release vs. maximum duration of temperature excursion above $500 \mathrm{C}$. The plot shows data from cubes: KC17-3C, KC17-4C, KC17-1C, KC17-2G and KC15-21C. 


\section{References:}

[1] G. Federici et al., J. Nucl. Mater., 290-293 (2001) 260.

[2] G. Federici, C H Skinner et al., "Plasma-material Interactions in Current Tokamaks and their Implications for Next-step Fusion Reactors", Joint report by the Princeton Plasma Physics Laboratory and the Max-Planck-Institut fuer Plasmaphysik. PPPL-3531/IPP9/128 January 2001, Nuclear Fusion in press.

[3] A. Gibson et. al., Phys. Plasmas, 5 (1998) 1839.

[4] R. J. Hawryluk, Reviews of Modern Physics, 70, (1988) 537-587.

[5] C. H. Skinner et al., J. Vac. Sci. Technol., A14 (1996) 3267.

[6] C. H. Skinner, et al., J. Nucl. Mater. 290-293 (2001) 486.

[7] P. Andrew et al., Fusion Eng.\& Des. 47 (1999) 233.

[8] R. A. Causey, W. R. Wampler and D. Walsh, J. Nucl. Mater., 176\&177 (1990) 987.

[9] W. Wang, W. Jacob and J. Roth., J. Nucl. Mater., 245 (1997) 66.

[10] J.W. Davis and A.A. Haasz, J. Nucl. Mater., 266-269 (1999) 478.

[11] K. Maruyama, W. Jacob and J. Roth., J. Nucl Mater 264 (1999) 56.

[12] S. Alberici et al., J. Nucl. Mater., 266-269 (1999) 754.

[13] C. H. Skinner, et al., Nuclear Fusion 39 (1999) 271

[14] R.E. Nygren, personal communication

[15] K.J. Hollis, R.G. Castro, C.J. Maggiore, A. Ayala, Nucl. Mater., 283 Part B (2000) 10851088

[16] C. H. Skinner et al., Proceedings of the $17^{\text {th }}$ IEEE/NPSS Symposium Fusion Engineering, San Diego, Ca. Oct 6-10, 1997, p.321. 
[17] B. L. Doyle and F. L. Vook, J. Nucl. Mater. 85\&86 (1979) 1019.

[18] S. T. Picraux and W. R. Wampler, J . Nucl. Mater. 93\&94 (1980) 853.

[19] B. Terreault J. Appl. Phys. 62 (1986) 152.

[20] H. Y. Guo and B. Terreault, Rev. Sci. Instrum. 64, (1993) 700.

[21] D. D. R. Summers et al., J. Nucl., Mater., 290-293 (2001) 496.

[22] W.M. Shu et al., to be submitted.

[23] D. Keroack and B. Terreault, J. Nucl. Mater. 231 (1996) 47.

[24] A. J. Bullen et al., J. Appl. Phys. 88 (2000) 6317.

[25] Quantronix Corp. Model 118F/CW-325 with Q scan marking head. For marking purposes the output is modulated with a Q switch, but this feature was not implemented in the present work.

[26] C. H. Skinner, et al., J. Nucl. Mater. 290-293 (2001) 486.

[27] Kleiber model 270B.

[28] G. Neuer, International Journal of Thermophysics 16 (1995) 257.

[29] National Optical \& Scientific Instruments Model DC3-420T .

[30] Fempto-Tech model 252400.

[31] N.P. Kherani and W. T. Shmayda, Fus. Tech. 21 (1992) 340.

[32] A. Nagy et al., Proceedings of the $17^{\text {th }}$ IEEE/NPSS Symposium Fusion Engineering, San Diego, Ca. Oct 6-10, 1997, p.317.

[33] O.A. Griesbach and J. R. Stencel, Proceedings of the $22^{\text {nd }}$ Midyear Symposium of the Health Physics Society, San Antonio, TX, Dec. 1988 p.374.

[34] N. P. Kherani and W. T. Shmayda, Fusion Technology 28, (1995) 893.

[35] B. E. Mills et al., J. Nucl. Mater., 162-164 (1989) 343. 
[36] W.R. Wampler et al., J. Vac. Sci. Technol. A6 (1988) 2111.

[37] G. R. Smolik et al., 'Evaluation of graphite/steam interactions for ITER', Idaho National Engineering Laboratory report, EGG-FSP-9154, September 1990.

[38] M. Paffett, personal communication.

[39] J. P. Quian et al., J. Nucl. Mater., 196-198 (1992) 653.

[40] J. G. van der Laan et al., J. Nucl. Mater., 196-198 (1992) 612. 


\section{External Distribution}

Plasma Research Laboratory, Australian National University, Australia

Professor I.R. J ones, Flinders University, Australia

Professor J oão Canalle, Instituto de Fisica DEQ/IF - UERJ , Brazil

Mr. Gerson O. Ludwig, Instituto Nacional de Pesquisas, Brazil

Dr. P.H. Sakanaka, Instituto Fisica, Brazil

The Librarian, Culham Laboratory, England

Library, R61, Rutherford Appleton Laboratory, England

Mrs. S.A. Hutchinson, JET Library, England

Professor M.N. Bussac, Ecole Polytechnique, France

Librarian, Max-Planck-Institut für Plasmaphysik, Germany

J olan Moldvai, Reports Library, MTA KFKI-ATKI, Hungary

Dr. P. Kaw, Institute for Plasma Research, India

Ms. P.J . Pathak, Librarian, Insitute for Plasma Research, India

Ms. Clelia De Palo, Associazione EURATOM-ENEA, I taly

Dr. G. Grosso, Instituto di Fisica del Plasma, Italy

Librarian, Naka Fusion Research Establishment, J AERI, J apan

Library, Plasma Physics Laboratory, Kyoto University, J apan

Research Information Center, National Institute for Fusion Science, J apan

Dr. O. Mitarai, Kyushu Tokai University, J apan

Library, Academia Sinica, Institute of Plasma Physics, People's Republic of China

Shih-Tung Tsai, Institute of Physics, Chinese Academy of Sciences, People's Republic of China

Dr. S. Mirnov, TRINITI, Troitsk, Russian Federation, Russia

Dr. V.S. Strelkov, Kurchatov Institute, Russian Federation, Russia

Professor Peter Lukac, Katedra Fyziky Plazmy MFF UK, Mlynska dolina F-2, Komenskeho Univerzita, SK-842 15 Bratislava, Slovakia

Dr. G.S. Lee, Korea Basic Science Institute, South Korea

Mr. Dennis Bruggink, Fusion Library, University of Wisconsin, USA

Institute for Plasma Research, University of Maryland, USA

Librarian, Fusion Energy Division, Oak Ridge National Laboratory, USA

Librarian, Institute of Fusion Studies, University of Texas, USA

Librarian, Magnetic Fusion Program, Lawrence Livermore National Laboratory, USA

Library, General Atomics, USA

Plasma Physics Group, Fusion Energy Research Program, University of California at San Diego, USA

Plasma Physics Library, Columbia University, USA

Alkesh Punjabi, Center for Fusion Research and Training, Hampton University, USA

Dr. W.M. Stacey, Fusion Research Center, Georgia Institute of Technology, USA

Dr. J ohn Willis, U.S. Department of Energy, Office of Fusion Energy Sciences, USA

Mr. Paul H. Wright, Indianapolis, Indiana, USA 
The Princeton Plasma Physics Laboratory is operated by Princeton University under contract with the U.S. Department of Energy.

\author{
Information Services \\ Princeton Plasma Physics Laboratory \\ P.O. Box 451 \\ Princeton, NJ 08543
}

Phone: 609-243-2750

Fax: 609-243-2751

e-mail: pppl_info@pppl.gov

Internet Address: http://www.pppl.gov 